\title{
Diagnóstico por imagem de Complexo Hiperplasia Endometrial Cística - Piometra (CHEC-P): Relato de caso
}

\author{
Imaging diagnosis of Cystic Endometrial Hyperplasia Complex - Pyometra (CHEC-P): Case report \\ Diagnóstico por imágenes del Complejo de Hiperplasia Quística Endometrial - Piometra (CHEC- \\ P): Reporte de caso
}

Recebido: 30/07/2021 | Revisado: 03/08/2021 | Aceito: 13/12/2021 | Publicado: 21/12/2021

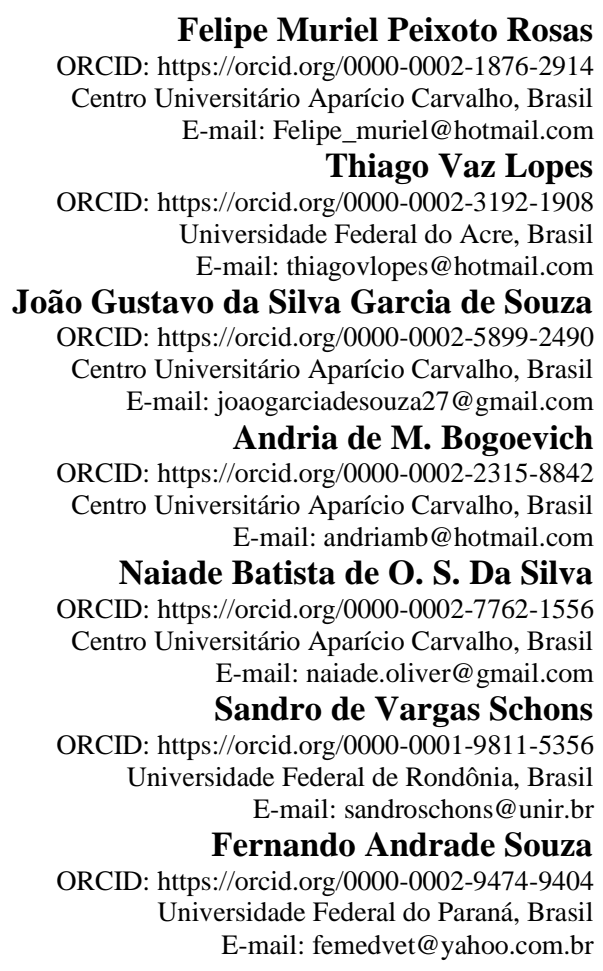

\section{Resumo}

O complexo Hiplerplasia Endometrial Cística - Piometra (CHEC-P) é amplamente encontrado no cotidiano da clínica médica de pequenos animais, sendo a principal enfermidade do trato reprodutivo da fêmea. Com isso, se faz necessário o diagnóstico rápido da doença, para que possa se estabelecer o melhor tratamento para a fêmea, sendo o principal método de diagnóstico a identificação por imagem ultrassonográfica. Uma cadela da raça poodle, não castrada, de 9 anos de idade foi levada pelo seu tutor em uma clínica veterinária de Porto Velho, Rondônia. A cadela apresentava apatia e depressão e no exame físico a cadela demonstrou abdome distendido e dor a palpação abdominal. Durante uma conversa, o tutor relatou dar anticoncepcional para a cadela à vários anos, o que fez com que o veterinário suspeitasse de início de uma possível piometra. Com isso, o médico veterinário pediu uma ultrassonografia abdominal. Após a realização da ultrassonografia, foi constatado Hiperplasia Endometrial Cística-Piometra (HEC-P), bem como esplenomegalia. O tratamento utilizado foi a ovariohisterectomia $(\mathrm{OH})$. A paciente se recuperou bem, recebeu alta alguns dias após a cirurgia e retornou para a averiguação de seu estado clínico e retirada dos pontos. Concluiu-se que a percepção do clínico e a utilização do diagnóstico por imagem ultrassonográfica foram de suma importância para a conclusão do caso.

Palavras-chave: Piometra; Rondônia; Ultrassonografia.

\begin{abstract}
The Cystic Endometrial Hyperplasia - Pyometra complex (CHEC-P) is widely found in the daily life of the medical clinic of small animals, being the main disease of the female reproductive tract. Thus, the rapid diagnosis of the disease is necessary, so that the best treatment for the female can be established, with the main diagnostic method being the identification by ultrasound image. A 9-year-old, uncastrated poodle dog was taken by her tutor to a veterinary clinic in Porto Velho, Rondônia. The bitch had apathy and depression and on physical examination the bitch showed distended
\end{abstract}


abdomen and pain on abdominal palpation. During a conversation, the tutor reported giving birth control to the bitch for several years, which made the veterinarian suspect the beginning of a possible pyometra. With that, the veterinarian ordered an abdominal ultrasound. After performing the ultrasound, Cystic Endometrial Hyperplasia-Pyometra (HEC $\neg-$ P) was found, as well as splenomegaly. The treatment used was ovariohysterectomy $(\mathrm{OH})$. The patient recovered well, was discharged a few days after surgery and returned to check her clinical status and remove the stitches. It was concluded that the clinician's perception and the use of ultrasound diagnosis were of paramount importance for the conclusion of the case.

Keywords: Pyometra; Rondônia; Ultrasound.

\section{Resumen}

El complejo Hiperplasia Quística Endometrial - Pyometra (CHEC-P) se encuentra ampliamente en la vida diaria de la clínica médica de pequeños animales, siendo la principal enfermedad del aparato reproductor femenino. Por tanto, es necesario el diagnóstico rápido de la enfermedad, para que se pueda establecer el mejor tratamiento para la mujer, siendo el principal método diagnóstico la identificación por imagen ecográfica. Un perro caniche no castrado de 9 años fue llevado por su tutor a una clínica veterinaria en Porto Velho, Rondônia. La perra presenta apatía y depresión y en el examen físico la perra presentaba abdomen distendido y dolor a la palpación abdominal. Durante una conversación, la tutora informó haber dado anticonceptivos a la perra durante varios años, lo que hizo sospechar al veterinario el inicio de una posible piometra. Con eso, el veterinario ordenó una ecografía abdominal. Tras la realización de la ecografía se objetivó Hiperplasia Quística Endometrial-Piometra (HECᄀ-P), así como esplenomegalia. El tratamiento utilizado fue la ovariohisterectomía $(\mathrm{OH})$. La paciente se recuperó bien, fue dada de alta a los pocos días de la cirugía y regresó para comprobar su estado clínico y retirar los puntos. Se concluyó que la percepción del clínico y el uso del diagnóstico ecográfico fueron de suma importancia para la conclusión del caso.

Palabras clave: Pyometra; Rondônia; Ultrasonido.

\section{Introdução}

Ao longo dos anos, com a vinda dos cães domésticos para os lares, havendo um estreitamento entre a relação humana com os cães, representando assim uma população de mais de um bilhão de cães domesticados no mundo (Gromper, 2014). Originados da espécie do lobo cinzento (Canis lupus), na época em que a pecuária e agricultura eram impulsionadas na região fértil em diversos países como Iraque, Líbia, Síria, e Jordânia, os cães (Canis familiaris) datando desse período o processo de domesticação canina (Silva, 2011).

Logo então com a grande relevância pertinente a superlotação e controle da origem dos animais de companhia e com a conscientização das pessoas responsáveis pelos animais, acabou criando-se métodos para prevenir a gestação com o intuito de controlar a população de cães, e reduzir a incidência de doenças reprodutivas de fêmeas (Gobello \& Castex, 2003).

Um exemplo clássico de patologia do trato reprodutivo de cadelas é o Complexo Hiperplasia Endometrial Cística/Piometra que é identificada em animais de companhia e se manifesta em cadelas mais velhas não castradas, (Feldman \& Nelson, 1996), e as nulíparas que apresentam maior risco de desenvolvimento a afecção em relação às primíparas e pluríparas (Niskanem \& Thrusfield, 1998). Noakes et al. (2001) estabeleceu que cerca de 4 a 5\% de todas as cadelas mostram esta enfermidade durante toda a vida. No entanto, Hagman (2004) relata que 25\% das cadelas de uma população podem desenvolver piometra até 10 anos de vida, já no estudo realizado Lopes (2021) foi demonstrada uma prevalência de $34 \%$ para manifestação do Complexo Hiperplasia Endometrial Cística/Piometra.

Esta patologia põe em risco a vida do animal por ocasionar intoxicação secundaria, pela liberação de endotoxinas produzidas pela infecção bacteriana, podendo ainda haver a ruptura uterina acarretando peritonite e insuficiência renal (Feldman \& Nelson, 1996). Estudos tem demostrado que a piometra vem cada vez mais se destacando como a principal patologia do sistema reprodutivo das fêmeas caninas, sendo difícil o diagnostico em outras espécies (Bidle \& Macintire, 2000).

Um dos meios de diagnósticos da patologia em questão é a ultrassonografia, e depois da década de 40 e 50 o ultrassom foi introduzido na rotina veterinária (Seoane et al., 2011; Oliveira, 2011), sendo este, um método não ionizante (Bradley, 2008). Esse método de diagnóstico vem se tornado um dos exames mais utilizados em medicina veterinária por auxiliar nos diagnósticos de várias doenças, e por apresentar diversas vantagens sobre o exame de radiografia, como a não utilização de radiação ionizante, sendo dessa forma bem mais seguro para o paciente e para o clínico operante (Poffenbarger \& Feeney, 1986; Rivers \& Johnston, 
1991). O presente trabalho tem como objetivo relatar o caso de uma paciente canina poodle de 9 anos, com diagnóstico de hiperplasia endometrial cística/piometra, tendo a ultrassonografia como forma de diagnóstico precoce.

\section{Relato de Caso}

Foi atendido um paciente da espécie canina, de raça poodle, gênero fêmea, não castrada, com idade de 9 anos na anamnese o tutor relatou que administrava medicação para interrupção do ciclo estral (Acetato de medroxiprogesterona), por vários anos consecutivos, sendo que o último cio havia ocorrido aproximadamente duas semanas antes da consulta, no exame físico foi observado abdome distendido e dor a palpação abdominal. Os achados clínicos associados a anamnese sugerem comprometimento envolvendo o trato reprodutivo da fêmea, tendo como principal suspeita o Complexo Hiperplasia Endometrial Cístico/Piometra, sendo solicitado a realização do exame ultrassonográfico com varredura abdominal, utilizando o equipamento MyLab Delta Esaote ${ }^{\circledR}$ com transdutores multifrequenciais, linear SL 3323 e microconvexo SC 3123, sendo realizado também as avaliações hematológicas e perfis renais e bioquímicos (ALT, FA, Ureia, Glicose e Creatinina).

\section{Resultado e Discussão}

No exame de imagem ultrassonográfico foi constado que o corpo e os cornos uterinos apresentavam volumes discretamente aumentados, apresentando $1,45 \mathrm{~cm}$ de diâmetro, estando preenchido por discreta quantidade de fluido intraluminal anecogênico heterogêneo, o endométrio apresentava-se ecogênico, espessado e heterogêneo, devido a presença de diversas estruturas arredondadas e anecogênicas, caracterizando assim os cistos, diagnosticando por tanto o Complexo Hiperplasia Endometrial Cística - Piometra (CHEC-P).

Ainda com a utilização da ultrassonografia, observou-se também o baço aumentado, uma esplenomegalia, podendo indicar a presença de um processo infeccioso e inflamatório, possivelmente por conta do CHEC-P, os demais órgãos não possuíam alteração, não sendo evidenciado a presença de líquido livre abdominal e peritonite.

Após o exame o clínico e ultrassonográfico, estando os parâmetros hematológicos e bioquímicos compatíveis com o CHEC-P, a cadela foi encaminha para o procedimento cirúrgico para a realização da ovariohisterectomia $(\mathrm{OH})$, técnica cirúrgica que consiste na remoção dos ovários e útero. A paciente teve uma recuperação satisfatória pós-cirúrgica, recebendo alta após alguns 3 dias da realização desse procedimento, realizando o retorno para a averiguação de seu quadro clínico e retirada dos pontos após 10 dias.

Como observado por Schweigert et al. (2009), o Complexo Hiperplasia Endometrial Cística - Piometra (CHEC-P) é uma patologia que comumente acomete cadelas mais velhas e não castradas. Estando compatível com o que aqui está sendo resultado, visto que se trata de uma paciente já em idade avançada e não castrada.

O uso da medicação à base de Acetato de medroxiprogesterona ao longo dos anos na cadela pode ser então o responsável por essa manifestação, sendo confirmado segundo o estudo feito por Sala et al. (2021) em que afirma, ser necessário apenas uma única dose aplicada desse anticoncepcional em cadelas hígidas, para a manifestação de patologias ligadas ao trato reprodutivo da fêmea, podendo variar de alterações leves a graves, como hiperplasia mamária, HEC e presença de secreção purulenta do trato genital da cadela. Silveira et al. (2013) demonstraram que a utilização de anticoncepcional foi um fator importante para a ocorrência de problemas obstétricos em cadelas e gatas ao longo de um ano, em um hospital veterinário, que levaram ao processo de ovariohisterectomia eletiva e terapêutica.

A paciente em questão apresentava um quadro de esplenomegalia, possivelmente em decorrência da CHEC-P. Isso também é observado por Ferreira et al. (2007), que relatam que essa ocorrência é devido a hematopoiese extramedular esplênica em casos de piometra. Feldman (2004) acrescenta outras possíveis causas, como septicemia e toxemia, que podem resultar em uma desidratação progressiva, choque, o coma, e possivelmente, levar o animal a óbito. 
A utilização da ultrassonografia na resolução do quadro, foi de grande importância, visto que confirmou a suspeita clínica, além de ter conseguido detectar a presença de uma esplenomegalia na cadela. Isso está de acordo com a afirmação feita por Alvarenga et al. (1995), de que a ultrassonografia é um método muito eficaz para o diagnóstico da piometra.

$\mathrm{O}$ tratamento utilizado foi a ovariohisterectomia $(\mathrm{OH})$, sendo este o método mais utilizado para tratar a piometra, visto que apresenta resultados imediatos, assim como descrito por Cruz-Pinto et al. (2015) e Prasad et al, (2018). Contudo, Lopes et al. (2021) apresenta o tratamento clínico terapêutico, possibilitando a conservação do trato reprodutor feminino e o retorno da possibilidade de gestação, entretanto não é indicado para cadelas com idade avançada, sendo justificado a utilização apenas para as que manifestem a patologia dentro da idade reprodutiva.

Desta forma a ultrassonografia é o exame padrão ouro para o diagnóstico precoce dessa doença por conseguir detectar a afecção mesmo que o animal não apresente alterações comportamentais e clínicos, mas para isto é fundamental que o operador ultrassonográfico tenha o devido conhecimento das técnicas ultrassonográficas, da anatomia e suas variações, tornando esta modalidade em operador dependente.

\section{Conclusão}

Conclui-se que a ultrassonografia é um método eficiente e precoce para o diagnóstico do Complexo Hiperplasia Endometrial Cística/Piometra, e a ovariohisterectomia é o método de resolução cirúrgico eficiente para cadelas que não estão em idade reprodutiva.

\section{Referências}

Bidle, D. \& Macintire, D. K. (2000). Obstetrical emergencies. Clinical Techniques in Small Animal Practice, 15(2): 88-93.

Bradley, W. G. (2008). History of Medical Imaging. Proceedings of the American Philosophical Society, 152(3): 349-361.

Feldman, E. C. \& Nelson, R. W. (1996). Canine and feline endocrinology and reproduction. (2a ed.), WB Saunders Company, $852-860$ p.

Feldman, E. C. (2004). O complexo hiperplasia endometrial cística/piometra e infertilidade em cadelas. In: Ettinger, S. J.; Feldman, E. C. Tratado de Medicina Interna Veterinária. (5a ed.), Guanabara Koogan, 2(162): 1632-1638.

Ferreira, L. N. et al. (2007). Esplenomegalia, com acentuada leucocitose, em decorrência de piometra. In: XVI Congresso de Iniciação Científica IX Encontro de Pós-Graduação, Pelotas.

Gobello, C. et al. (2003). A study of two protocols combining aglepristone and cloprostenol to treat open cervix pyometra in the bitch. Theriogenology, 60(5): 901-908.

Gromper, M. E. (2014). One billion dogs? What does that means? <http://blog.oup.com/2014/03/one-billion-dogs-wildlife-conservation>

Hagman, R. (2004). New aspects of canine pyometra - studies on epidemiology and pathogenesis.Acta Universitatis Agriculturae Sueciae.

Lopes, T. V. (2021). Tratamento terapêutico da piometra canina: um velho problema, uma nova abordagem. Tese de doutorado para obtenção do grau de Doutor em Ciência Animal pela Universidade Federal do Acre, UFAC. $92 \mathrm{f}$

Lopes, T. V. et al. (2021). Perfil de sensibilidade antimicrobiana de bactérias isoladas, de piometra em cadelas, frente à infusão uterina de gentamicina (Gentrin $\left.{ }^{\circledR}\right)$. Pesquisa, Sociedade e Desenvolvimento, 10(7): e26810715170, 2021. 10.33448/rsd-v10i7.15170. https://rsdjournal.org/index.php/rsd/article/view/15170.

Niskanen, M., \& Thrusfield, M. V. (1998). Associations between age, parity, hormonal therapy and breed, and pyometra in Finnish dogs, Veterinary Record, 143(18): 493-498

Noakes, D. E. Dhaliwal, G. K. \& England, G. C. (2001). Cystic endometrial hyperplasia/pyometra in dogs: a review of the causes and pathogenesis. Journal of reproduction and fertility. $57: 396-406$.

Oliveira, K. S. (2007). Complexo Hiperplasia Endometrial Cística. Acta Scientiae Veterinariae, 35: 270-272.

Poffenbarger, E. M. \& Feeney, D. A. (1986). Use of grayscale ultrasonography in the diagnosis of reproductive disease in the bitch: 18 cases (1981-1984). Journal of the American Veterinary Medical Association, 189(1): 90-95.

Rivers, B. \& Johnston, G. R. (1991). Diagnostic imaging of the reproductive organs of the bitch. Veterinary Clinics of North American. Small Animal Practice, 21(3): 437- 466.

Sala, P. L. et al. (2021). [Uma única aplicação de anticoncepcional causa alterações patológicas em cadela?]. Arquivo Brasileiro de Medicina Veterinária e Zootecnia, 73(3): 752-756. 
Research, Society and Development, v. 10, n. 17, e58101718918, 2021

(CC BY 4.0) | ISSN 2525-3409 | DOI: http://dx.doi.org/10.33448/rsd-v10i17.18918

Schweigert, A. et al (2009). Complexo Hiperplasia Endometrial Cística (Piometra) Em Cadelas - Diagnóstico E Terapêutica. Colloquium Agrariae, 5(1): 32 -37.

Seoane, M. P. R., Garcia, D. A. A. \& Froes, T. R. (2011). A história da ultrassonografia veterinária em pequenos animais, Archives of Veterinnry Science, 16(1): $54-61$.

Silva, D. P. (2011). Canis familiaris: Aspectos da Domesticação (Origem, Conceitos, Hipóteses). 46f. Monografia (Bacharelado em Medicina Veterinária)— Universidade de Brasília, Brasília.

Silveira, C. P. B. et al. (2013). Estudo retrospectivo de ovariossalpingo-histerectomia em cadelas e gatas atendidas em Hospital veterinário Escola no período de um ano. Arq. Bras. Med. Vet. Zootec., 65(2): 335-340. 